\title{
Arquitectura del Paisaje: Retrospectiva y prospectiva de la disciplina a nivel global y latinoamericano. Enfoques, tendencias, derivaciones
}

\author{
Landscape architecture: Retrospective and prospective of the discipline on a global \\ and latinamerican level. Approaches, trends, derivations
}

<Resumen>

En una posición intermedia e integradora entre las ciencias naturales y las ciencias sociales, la Arquitectura del Paisaje constituye una base conceptualmente transversal, sinérgica y superadora de los enfoques tradicionales que han caracterizado el accionar sobre el territorio, la sociedad, el medioambiente y sus problemáticas. Este artículo revisa los principales enfoques desarrollados en el estudio y práctica de la disciplina, рага luego orientar de manera prospectiva diversas derivaciones contemporáneas a nivel global.

$<$ Abstract $>$

In an intermediate and integrative level between natural and social sciences, landscape architecture is conceptualy transverse and synergistic oriented towards overcoming traditional approaches, that have characterized the actions over territory society environment and its critical problematics. This article reviews the main approaches developed in the study and practice of this discipline to focus their prospective contemporary ramifications on a global level.

¿PALABRAS CLAVE>

TRADICIÓN PAISAJISTA / ECOLOGÍA DEL PAISAJE / ARQUITECTURA DEL PAISAJE / TERCER PAISAJE (TIERS-PAYSAGE) / ARTIALIZACIÓN

\section{KKEYWORDS>}

LANDSCAPE TRADITION \& LANDSCAPE ECOLOGY LANDSCAPE ARCHITECTURE / THIRD LANDSCAPE (TIERS-PAYSAGE) / ART I ALIZATT ION
Introducción. Referencias históricas y evolución del hacer paisajista

Resulta sumamente complejo estructurar un discurso concluyente en torno a la noción de Paisaje, debido principalmente a la multiplicidad de usos que adquiere el término desde sus distintas acepciones en diferentes disciplinas y, desde hace algunos años, por su adscripción generalizada en aquellos discursos ligados a las problemáticas del medioambiente, la sustentabilidad y la producción del espacio público. El presente artículo trata de establecer un estado del arte respecto a estas temáticas, revisadas desde la arquitectura del paisaje como andamiaje teórico, metodológico y proyectual.

Una posibilidad de construcción retrospectiva es centrarse en la diferenciación -ya clásicade las diversas escuelas y tradiciones paisajistas, las cuales se distribuyen histórica y geográficamente en distintas latitudes. Desde ahí es posible distinguir en forma genérica dos grandes vertientes: la tradición anglosajona, radicada principalmente en Estados Unidos

\footnotetext{
Arquitecto Universidad de Chile. Magíster en Paisaje, Medioambiente y Ciudad, obtenido con distinción máxima en el Programa ALFA de la Unión Europea, desarrollado en la Universidad Nacional de La Plata, Argentina. Diplomado en Preparación y Evaluación de Proyectos, Escuela de Posgrado Universidad de Chile. Coordinador Académico de la Escuela de Arquitectura del Paisaje, Universidad Central de Chile. Académico en la Facultad de Arquitectura y Urbanismo, Universidad de Chile. Miembro representante en Chile del Foro Latinoamericano de Ciencias Ambientales - FLACAM.
} 
y Gran Bretaña, se ha ocupado del paisaje desde su concepción como hecho espacial y ambiental, en el estudio y manejo de los componentes físicos -suelo, agua, flora y fauna- del territorio. Entre los referentes más cercanos a nuestros días se encuentran lan Mcharg ${ }^{1}$ y Richard Forman.

Desde otro ángulo, la tradición EuropeaMediterránea -por algunos autores también llamada latina- centra su atención en la dimensión social y cultural del paisaje, como expresión estética de las formas de vida de la sociedad en un determinado contexto espacial y temporal ${ }^{2}$. Como disciplina derivada de la geografía y estimulada por la representación pictórica impresionista del siglo xIx, el Paisaje en el contexto europeo es parte fundamental de la planificación territorial, considerado patrimonio a resguardar, restaurar o promover, dada su relevancia como reflejo de las particularidades culturales de una determinada región. Testimonio de ello es toda la institucionalidad que se ha construido en torno al Paisaje, desde la Convención de Florencia en el año 2000, luego la Ley Europea del Paisaje, hasta la elaboración de instrumentos precisos tales como las Cartas de Paisaje y los Catálogos de Paisaje. En cuanto a autores referenciales vigentes, se puede nombrar a Augustin Berque, Pierre Donadieu, Alain Roger, Javier Maderuelo y Raffaele Milani, entre otros.

No obstante, referirse de manera tan estructurada y bipolar a la noción de Paisaje implica actualmente un dilema aún mayor, capaz de reducir y agotar la riqueza que se esconde tras su ambigüedad y dinámica. Si nos adentramos en la vida y obra de autores representantes de un lado, nos damos cuenta que aparecen rasgos distintivos del lado contrario. Ocurre, por ejemplo, con la obra de Jean Le Nôtre ${ }^{3}$, catalogada generalmente desde su valor estético, pero que guarda en sí rigurosos métodos científicos de manejo hídrico y de organización espacial de las especies en base a estudios de soleamiento. Asimismo, distintos profesionales del paisaje -entre ellos, por ejemplo, Peter Latz, Martha Schwartz o Peter Walker- transitan con libertad entre ambas tradiciones, abordando en su trabajo temáticas ligadas tanto a lo ecológicoambiental como a lo estético-cultural.

«Orpheus Leading Eurydice» (1861), obra de Jean-Baptiste-Camille Corot (fuente: http://www.reproarte.com)

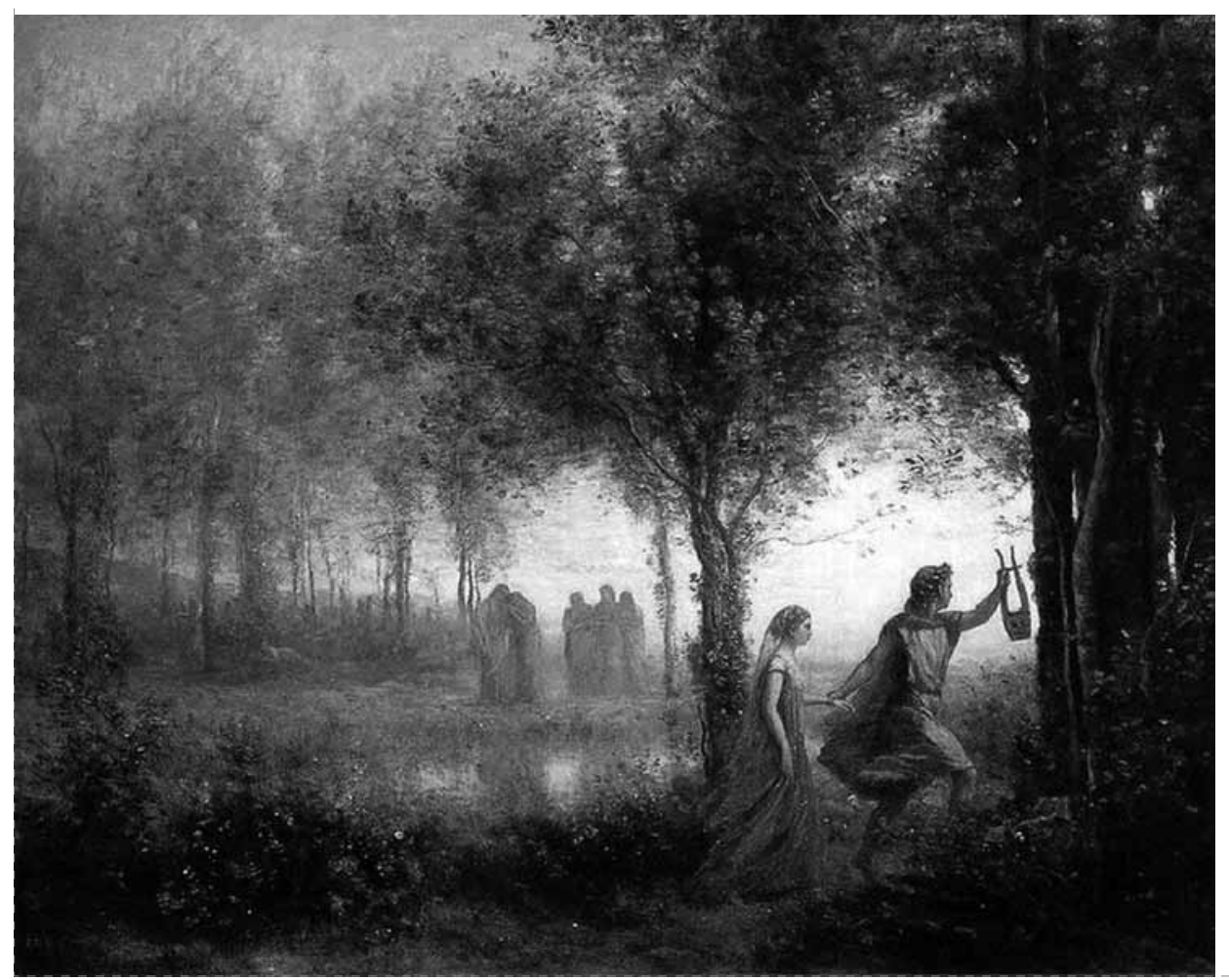

Paisaje, una disciplina transversal e integradora. Enfoques prospectivos

Para enriquecer la exploración se propone esta hipótesis prospectiva experimental, la que se establece en función de cualidades temáticas y epistemológicas, que incluirán de todas formas -e inevitablemente- las distinciones establecidas por la categorización clásica antes enunciada. En términos generales, la práctica y la academia del paisaje se han enfocado a través del tiempo desde al menos tres perspectivas paralelas.

En primer lugar, existe una perspectiva que ha definido históricamente al Paisaje como categoría estética ligada a las manifestaciones del arte, esencialmente a la pintura, a la fotografía y de manera más reciente al Land Art. En efecto, la noción de paisaje nace como categoría estética. Antes de su invocación en disciplinas como la geografía y el urbanismo, el término paisaje o más bien landscape -que surge como derivación del concepto holandés de landschap, a comienzos del siglo XvI- designaba a un género pictórico del Renacimiento en el norte de Europa, que tuvo su apogeo con la pintura al aire libre de la escuela de Barbizón y con los Impresionistas, en el siglo xIx (Donadieu, 2006).

La pintura del paisaje representaba escenas de la naturaleza y del mundo rural, contribuyendo a modificar la relación cultural entre la sociedad y el territorio. A través de la pintura y luego con la fotografía, los artistas conquistaron para el resto de la sociedad aquellos paisajes lejanos y desconocidos, como la montaña, el litoral y los bosques; al trabajarlo en forma estética participaron en la pacificación del territorio, generando la admiración por escenarios que luego serían objeto de atractivo turístico (grand tour) -como

lan Mcharg (1920-2004), académico de la Universidad de Pennsylvania, revolucionó la enseñanza de la arquitectura del paisaje, integrando estrechamente el trabajo de diseño realizado en los talleres con el trabajo científico de laboratorio. Su método de construcción de cartografías integradas por múltiples capas para revelar potenciales y limitaciones en el paisaje se considera antecesor directo de los Sistemas de Información Geográfica, hoy utilizados en el planeamiento de manera extensiva alrededor del mundo.

En su raíz etimológica, el término paisaje proviene del latino pagus, que significa tierra (país); una porción de territorio habitada y apropiada por un grupo social determinado. De la misma raíz proviene el término paisano, concepto que describe a un habitante de una región -o país- en particular (Roger, 2007).

3 Jean Le Nôtre, jardinero del rey Luis XIII. Diseñador entre otros proyectos de los jardines del Palacio de Versalles. 
Spiral Jetty, proyecto de land art de R. Smithson en Utah, EE.UU. (fuente: http://madsilence.wordpress.com).

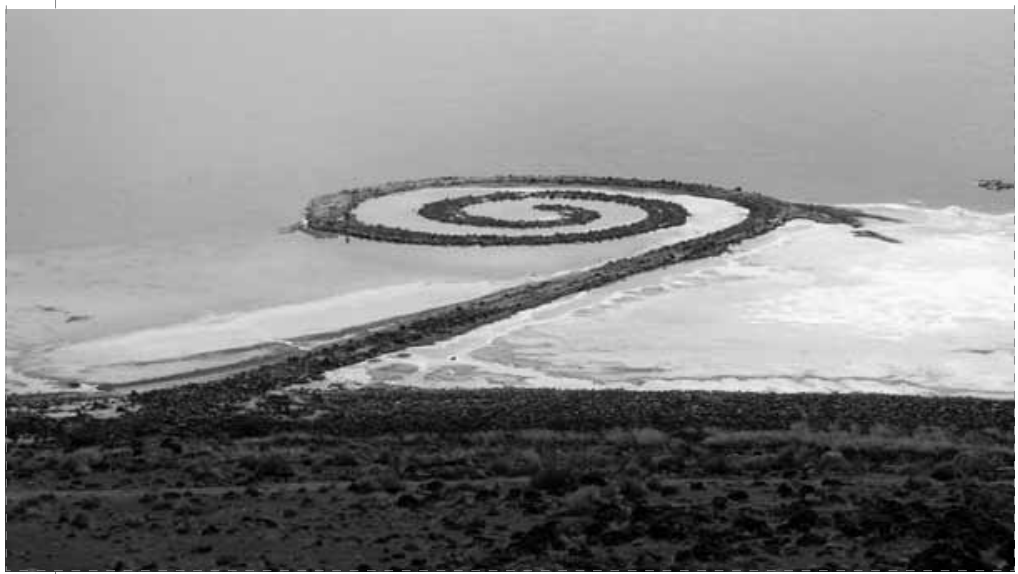

Tratamiento de relieves y cultivos, proyecto de Bernard Lassus en torno a la autopista A 85 , en Francia (fuente: http://www. bernard-lassus.com/page15.htm).

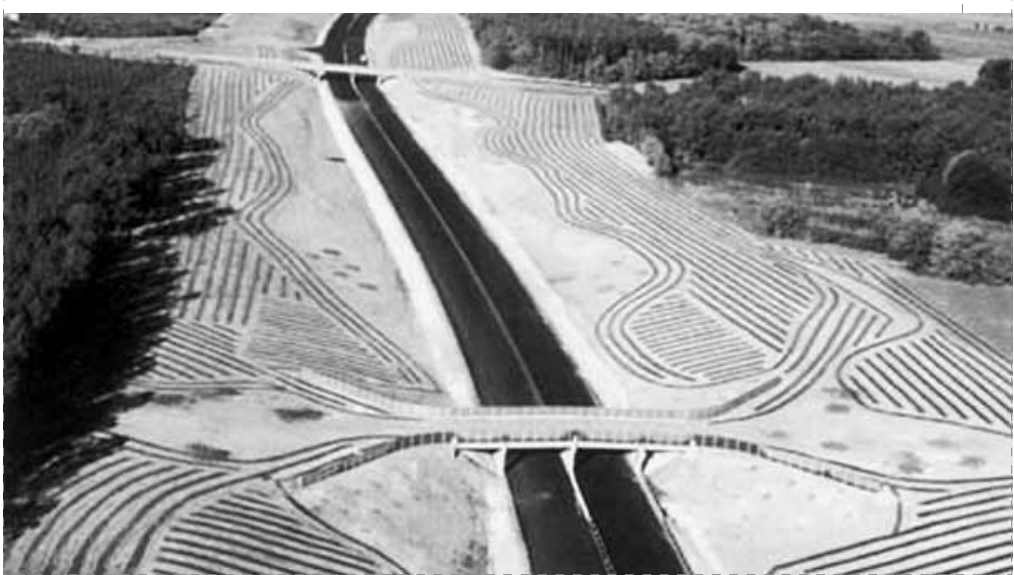

el desarrollo de centros invernales y balnearios litorales- y de representación cultural de las sociedades, a través de la idealización de campiñas agrícolas, bordes costeros, valles y viñedos, entre otros paisajes.

Aquella operatoria de aprehensión territorial desde el arte ha sido denominada en la actualidad bajo el concepto de artialización. Según explica Roger (2007), el proceso de artialización es una forma de interpretación del territorio percibido a través de la sensibilidad artística, construyendo una mirada cultural que lo devuelve como paisaje, es decir, es el proceso artístico que transforma un determinado territorio (país) en paisaje. Ello ha sido explorado, como se ha señalado, desde disciplinas tales como la pintura en el renacimiento tardío, pasando por la fotografía y las artes cinematográficas, hasta experiencias más contemporáneas de land art ${ }^{4}$, earth work e incluso en torno a proyectos de arquitectura del paisaje ${ }^{5}$.

El rol de estos paisajes pintorescos, construidos desde la artialización, sigue vigente hoy. Ellos reproducen las huellas arquetípicas que demarcan el territorio y redefinen la relación entre el ser humano -habitante y/o visitante- y su entorno, proponiendo imaginarios que inspiran a la sociedad a conservar, recuperar y proyectar su espacio de vida, por medio de imágenes iconográficas que pasan a formar parte de su patrimonio cultural.
En segundo término, desde las ciencias ambientales, el paisaje constituye un modo de organización de los componentes bióticos y abióticos de la superficie terrestre, considerando, entre otros temas, los procesos geomorfológicos y la distribución de la flora y fauna en el espacio geográfico, a lo largo del tiempo (Di Pace et al, 2004).

Ejemplo de este enfoque es la Ecología del Paisaje $^{6}$, rama de las ciencias ambientales que estudia la estrecha interacción entre las matrices espaciales y los procesos ecológicos, orientada a la comprensión de las causas y consecuencias que generan la heterogeneidad espacial a lo largo de diversos rangos escalares. Enfatizando métodos de análisis cuantitativos, recurre frecuentemente a estadísticas espaciales, modelos ecológicos y sistemas de información geográfica (SIG) para la interpretación del territorio. Esta perspectiva científica del paisaje es alimentada por disciplinas como la Botánica, la Zoología, la Biogeografía y la Ecología, poniendo un meno énfasis a su valor estético, así como a su ro social y cultural. En la práctica, la Ecología del Paisaje ha derivado hacia nuevas metodologías de planificación y gestión territorial, aportando técnicas precisas en el modelamiento de procesos ambientales, así como también estrategias de intervención dinámicas, en sintonía con la condición cambiante y compleja del territorio?.
En medio de ambas concepciones, y nutrida fundamentalmente por discursos y experiencias provenientes de la Arquitectura y el Urbanismo, podemos ubicar a la Arquitectura del Paisaje. El inicio oficial de la disciplina es atribuible a quién estableció su denominación hacia fines del siglo xix: Frederick Law Olmsted, creador del Central Park en Nueva York y de la noción de Parque Nacional, aplicado a Yosemite National Park entre otros tantos casos (Ábalos, 2008).

El término Landscape Architect fue utilizado por Olmsted para reemplazar al de Landscape Gardener-herencia del paisajista inglés Humphry Repton- centrando la atención en una idea de construcción del espacio público moderno a través del concepto de parque, y no ya en la aspiración de una naturaleza sublime contenida en el paisajismo de jardines ${ }^{8}$. Más allá de cuestiones semánticas, este enfoque alternativo permitió reconocer el valor-ecológico, social y monetario- de la presencia activa de naturaleza en la ciudad y en el territorio.

Como señala Ábalos, «todavía hoy pensamos la naturaleza en gran medida como Olmsted la vio, esto es, como un monumento al que hemos de proteger para nuestro disfrute y el de generaciones venideras; como un enorme sistema de espacios públicos articulado en el interior de esa ciudad, ahora global, en la que vivimos» (Ábalos, 2005: 16).

4 Entre los referentes más importantes del Land Art, cabe señalar a Robert Smithson, con la obra Spiral Jetty ejecutada en Great Salt Lake, Utah, en 1970.

Algunos arquitectos paisajistas -como Alain Roger y Bernard Lassus- han explorado los límites de la arquitectura del paisaje desde intervenciones que podrían considerarse como land art.

6 Richard Forman constituye un referente contemporáneo de la Ecología del paisaje, destacándose entre sus publicaciones: Landscape Ecology (1986) y Land Mosaics (1995). Así también lan Mchargh, autor ya señalado antes.

Una de las estrategias de planificación ecológica del territorio más difundida a nivel mundial la constituye los Planes de Manejo integrado de Cuencas (Gómez Orea, 1994).

Esta noción puede ser también asimilada a las ideas paisajísticas de otros autores, entre los que destaca Le Nôtre y sus jardines barrocos. 
Esa visión moderna del arquitecto del paisaje parece guiar también en la actualidad las prácticas y discursos contemporáneos, evolucionando hacia una mayor (y hasta generalizada) sensibilización de los profesionales del paisaje ante las problemáticas ambientales y sociales del territorio, especialmente en torno al hábitat urbano.

La Arquitectura del Paisaje en la producción del hábitat contemporáneo. Tendencias y derivaciones

El concepto de Arquitectura del Paisaje responde hoy a nuevos requerimientos de intervención, diseño y ordenamiento territorial; escenarios complejos donde se encuentran estrechamente ligadas y superpuestas las problemáticas sociales, económicas, ecológicas, culturales y estéticas del espacio habitado. En tal sentido, el paisaje se constituye como una modalidad de lectura e intervención a través del proyecto, en una posición intermedia e integradora entre las ciencias sociales, las ciencias naturales y las disciplinas del arte.

A nivel internacional, equipos conformados por diversos profesionales nos presentan un amplio repertorio de proyectos que entrelazan la dimensión estética, social y ambiental de la Arquitectura del Paisaje. En Alemania, por ejemplo, y extendido a distintas ciudades europeas, se halla el trabajo del estudio Latz+Partners. A cargo de Peter Latz se desarrolla en torno a sus proyectos una idea de resignificación de los espacios industriales abandonados: antiguas fábricas, sitios mineros e infraestructuras urbanas en desuso. Mediante un proceso proyectual denominado paisajismo postindustrial se conjuga la artialización de los componentes artificiales del paisaje, la introducción de biota apta para fitorremediar suelos erosionados y la creación de escenarios programáticos que incorporan a múltiples actores sociales. Intervenciones como el Parque de Duisburg Nord sintetizan en sí mismos diversos enfoques históricos de la disciplina paisajista.

Cercana a esta visión se encuentra la postura -principalmente teórica- de Gilles Clemènt y su concepto de Tercer Paisaje ${ }^{9}$ (Tiers-

El manejo de cuencas se aplica desde una escala territorial urbana, hasta niveles transnacionales. En la imagen, el plano de maneo de la cuenca del río Uruguay, que reúne territorios de Brasil, Uruguay y Argentina (fuente: www.montevideo.gub.uy/pot/miguelete.pdf).
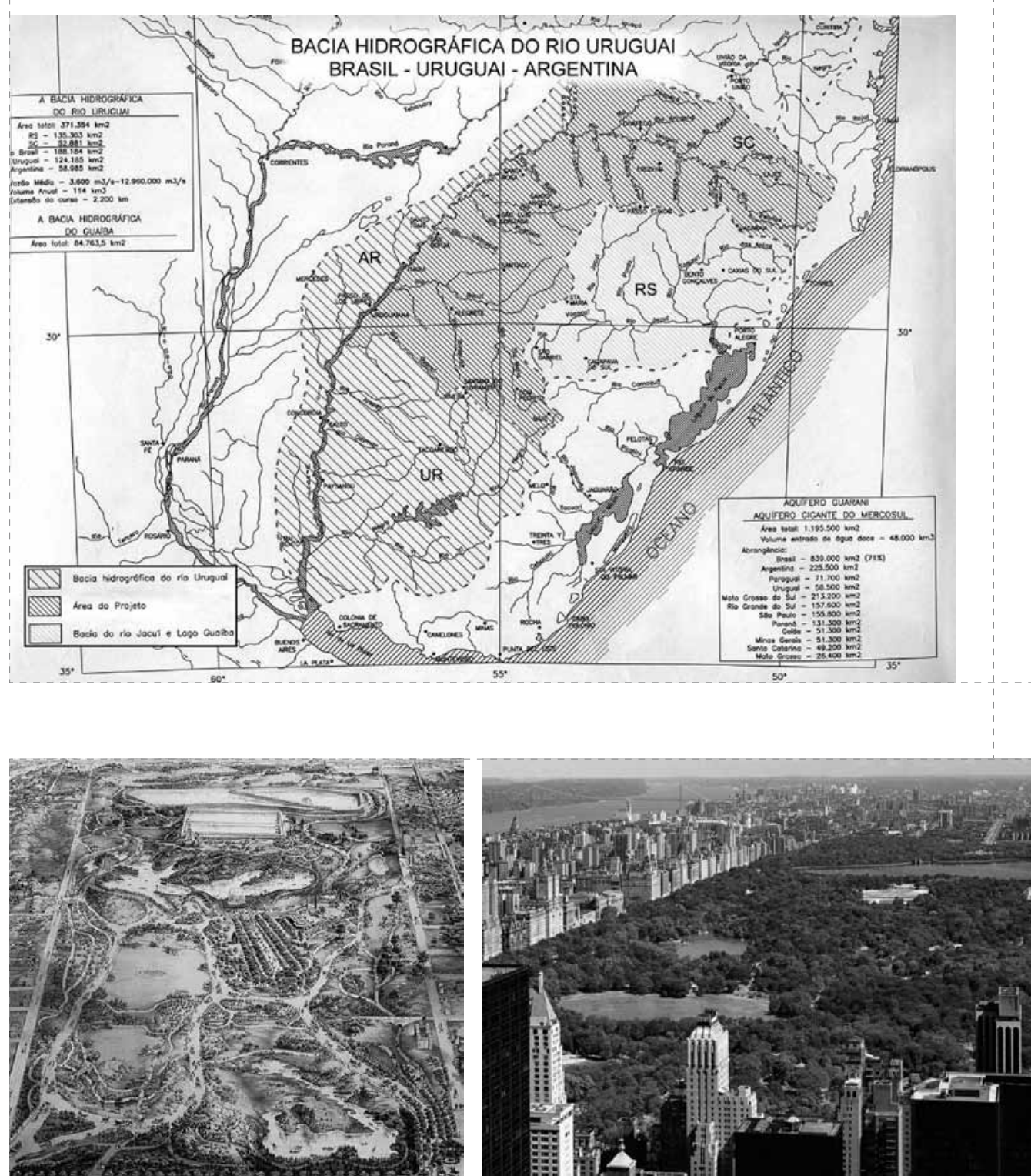

Izquierda, vista a vuelo de pájaro -bird eye-del Central Park proyectado por Olmsted en Nueva York. Derecha, vista actual del parque (fuente: http://thesituationist.files.wordpress.com/)

Paysage), el cual designa una nueva forma de ver e interpretar los residuos urbanos: áreas degradadas, abandonadas, desechadas, olvidadas, perdidas o subutilizadas principalmente en las periferias urbanas, en el ecotono entre el territorio antrópico planificado y el territorio natural aún no ocupado por el hombre. Históricamente designados desde una valoración negativa - wasteland, terrain vague o no lugar ${ }^{10}$ - esta visión paisajista nos permite comprender estos residuos territoriales desde una mirada positiva construida desde el paisaje. En tal sentido, se entiende que los vacíos residuales que conforman el tercer

\footnotetext{
Según Clemènt, como primer paisaje se entiende al ambiente clímax, constituido por territorios lejanos de las actividades humanas, donde las especies se suceden en equilibrio, con alto nivel de biodiversidad. El segundo paisaje se define como el conjunto de espacios caracterizados por la presencia continua de actividades humanas, territorios

antrópicos en constante ocupación y transformación. Ejemplo de ellos puede ser la ciudad, los terrenos agrícolas, un parque urbano o los sitios industriales (Clemènt, 2007).

10 Términos acuñados por los autores Kevin Lynch, Ignasi de Solà-Morales y Marc Augé, respectivamente.
} 
Imágenes del parque Duisburg Nord, obra de Latz+Patrners

(fuente: http://www. latzundpartner.de)
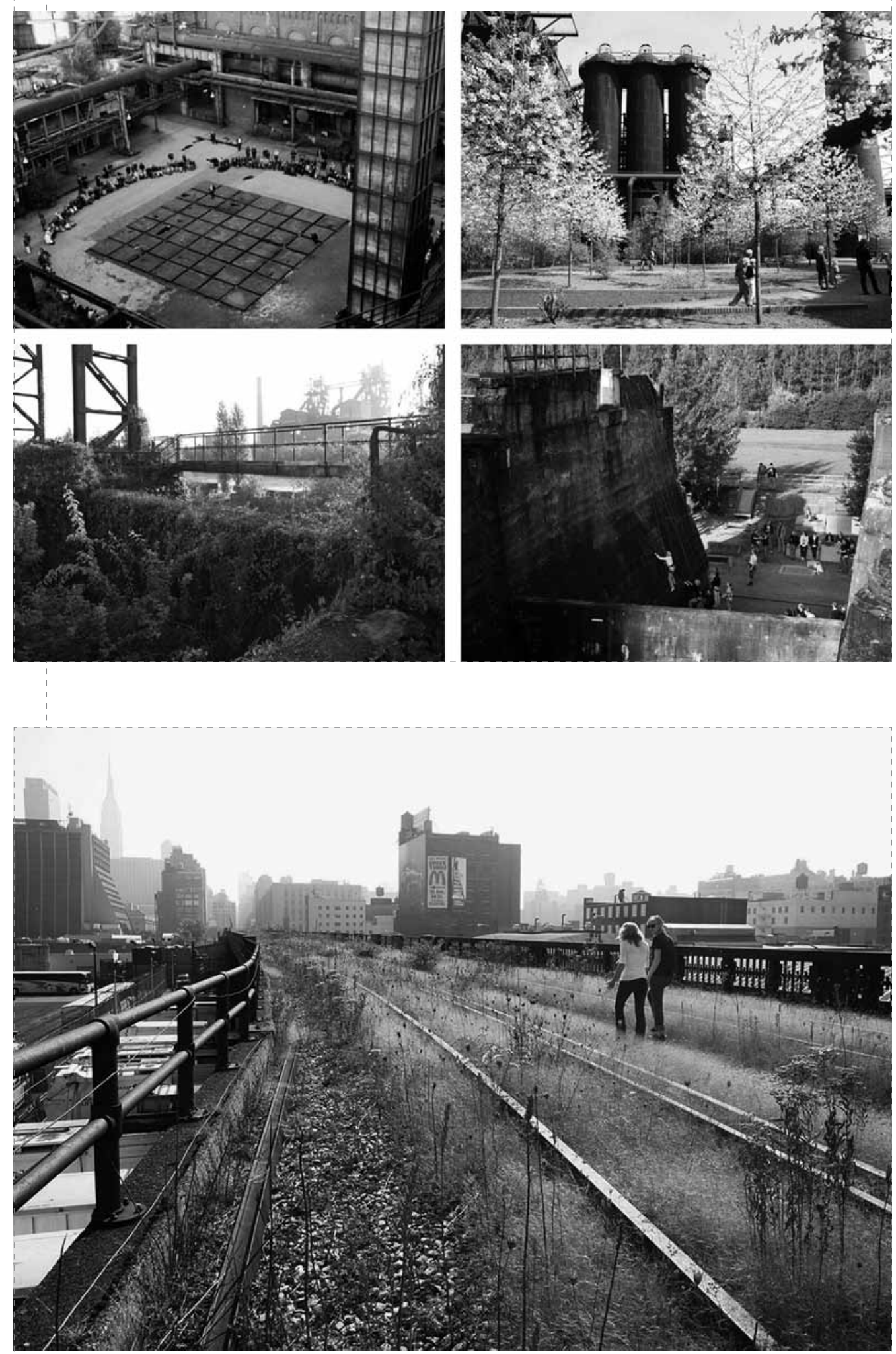

Imagen del viaducto High Line, en Nueva York: reducto del Tercer Paisaje.

Para reutilizar esta infraestructura que cruza la ciudad, fue promovido un concurso de ideas ganado por la firma Diller Scofidio + Renfro, cuya propuesta se basa en los preceptos de Clemènt (fuente: http://www. thehighline.org/). paisaje constituyen reductos de biodiversidad ecológica y escenarios de expresión sociocultural que estructuran y sostienen el territorio periurbano, pudiendo transformarse potencialmente en nuevas tipologías de espacios verdes públicos

En Norteamérica, en tanto, James Corner y su estudio Field Operations han desarrollado interesantes propuestas para variados y complejos escenarios metropolitanos. Uno de los proyectos más destacados es Fresh Kills Parkland, monumental reconversión de los antiguos vertederos de la ciudad de Nueva York para transformarlos en uno de los referentes más importantes de la arquitectura del paisaje actual. Combinando una rigurosa ingeniería ambiental para gestionar los residuos urbanos y el manejo ecológico de humedales, junto a la sensibilidad estética para crear escenarios de encuentro social en sintonía con la cultura contemporánea, Fresh Kills retoma la tradición de Central Park, reinterpretada hoy en la era de la globalización y de los discursos prosustentabilidad.

En Asia, la milenaria cultura china es la base conceptual que guía el trabajo del grupo Turenscape, y su director Kong Jiang Yu. Tomando como material de proyecto las preexistencias de usos, símbolos y tipologías de la cultura china, sus propuestas constituyen una posibilidad de relectura e intervención contemporánea en la construcción de nuevos espacios públicos urbanos, en el vertiginoso contexto de crecimiento y expansión de las ciudades orientales. Los diversos proyectos desarrollados por Turenscape informan de os resultados que la arquitectura de paisaje puede lograr en el territorio urbano: desde sus simples posibilidades sensoriales y recreativas, hacia complejas decisiones que combinan variables técnicas y estéticas, las cuales son fundamentadas a través de su impacto ecológico y social; logrando traer a las nuevas generaciones las memorias del pasado a través de una puesta en escena totalmente contemporánea.

Desde América Latina, la arquitectura de paisaje ha ido construyendo su propia tradición, manifestando la condición mestiza de lo latinoamericano, desde la paleta expresionista y las geometrías orgánicas de Burle Marx, hasta las interpretaciones de la identidad telúrica reveladas a través de la tectónica en los proyectos de Carlos Martner En torno a estos referentes se localizan diversas tendencias que replican en la realidad local modelos norteamericanos o europeos, tanto en el ámbito del diseño urbano, como en el paisajismo de jardines públicos y privados. 
Ejemplos como el parque Micaela Bastidas ${ }^{11}$ en Buenos Aires, o el parque Bicentenario ${ }^{12}$ en Santiago, logran reinterpretar con éxito referencias globales -principalmente operadas desde la lógica de Olmsted-para ser instaladas en el contexto local.

Explorando enfoques más alternativos -en sintonía con temas como el tercer paisajeaparecen conceptos que intentan poner sobre la mesa las problemáticas propias que afectan al sur del continente. La idea de paisajismo xerófito, por ejemplo, revela la necesidad de establecer un cambio de imagen de lo que se quiere y ofrece como proyecto de paisaje. Bajo directrices de eficiencia energética y sustentabilidad ecológica, se establece una estrategia de actuación orientada hacia una estética ambiental coherente con la biogeografía de los climas mediterráneos y semidesérticos, propios de países como Chile.

Generado desde una aspiración de sustentabilidad con énfasis en la dimensión social, la idea de parques agroculturales urbanos introduce la noción de combinar bajo la figura del parque público espacios productivos de agricultura urbana junto a escenarios de recreación y educación ambiental, contemplando el uso de terrenos baldíos y degradados principalmente en contextos de periferia urbana. Junto a ello, la reutilización de desechos orgánicos para compostaje y la recuperación de aguas urbanas para regadío, promueven la comprensión de estos espacios como plataformas de integración social, y como dispositivos de gestión ambiental en la ciudad.

Primero desde la construcción de una imagen ambiental, y luego desde la proposición de programas alternativos para los espacios abiertos, ambas posturas colaboran en la apertura de nuevas derivaciones de la arquitectura del paisaje más sensibles hacia la realidad local, de las cuales pueden surgir inéditas estrategias de intervención y tipologías de proyecto.

\section{Reflexiones finales}

Repensar el espacio urbano y el territorio desde la Arquitectura del Paisaje permitirá individualizar lugares, estrategias y programas

Imagen de Fresh Kills Parkland, obra de Field Operations (fuente: TOPOS International Review of Landscape Architecture and Urban Design. Número 51).
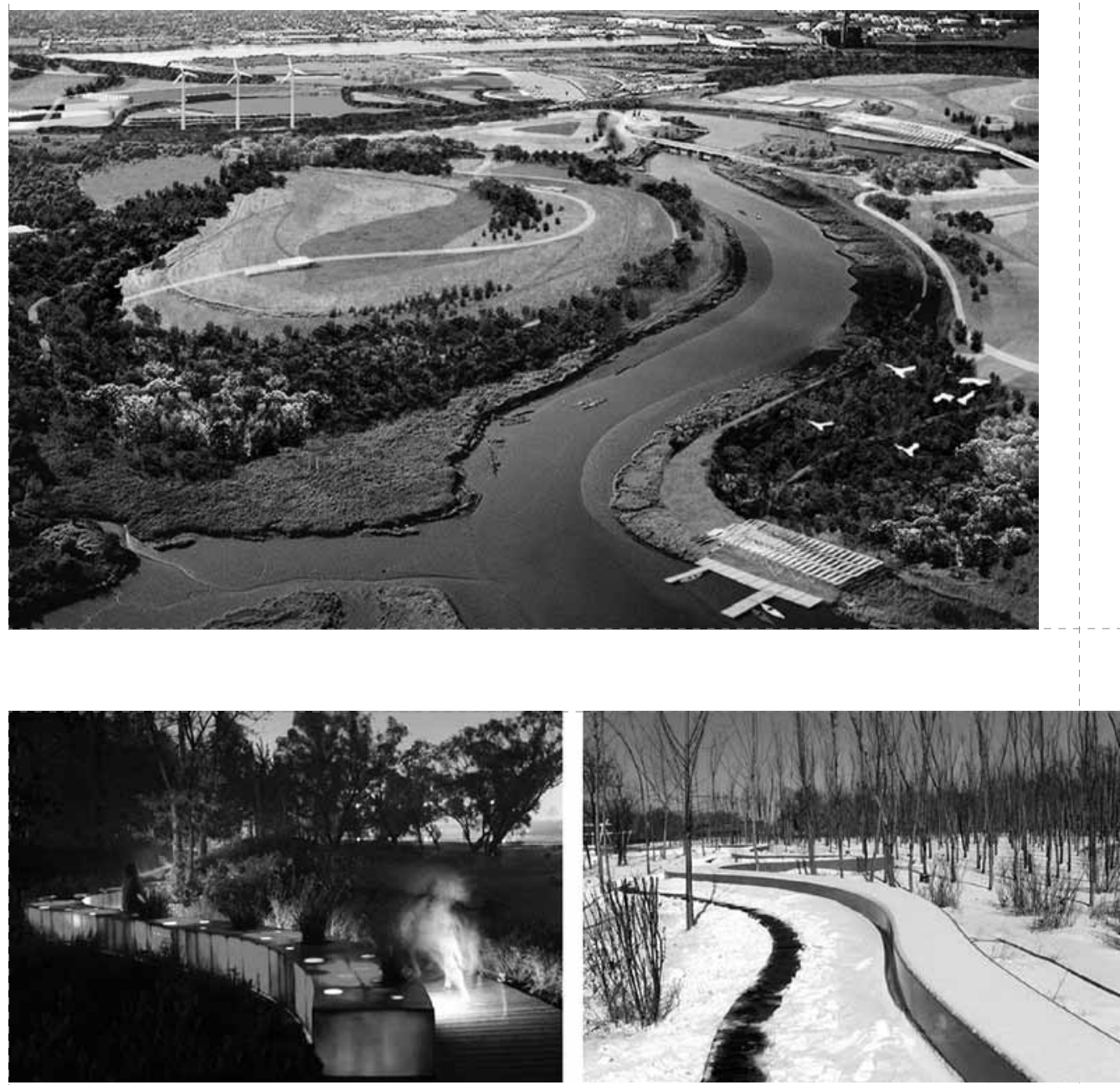

Imágenes del Proyecto The Red Ribbon, para el Tanghe River Park del estudio chino Turenscape (fuente: http://www. turenscape.com)

para equilibrar el déficit medioambiental de la ciudad, su oferta de ocio y productividad, mejorando la calidad de vida y la sustentabilidad urbana en el marco de la economía global desde el contexto local. Ello demanda el desarrollo de análisis e intervenciones ligados a una concepción tanto estética como productiva de los elementos naturales, desde la experimentación de metodologías en las que confluyan los aspectos económicos, arquitectónicos, urbanísticos, ecológicos y sociales, para generar nuevas visiones y concepciones de ciudad, construyendo en suma una mirada actualizada sobre el medio territorial de nuestras sociedades contemporáneas.

Reconociendo la diferenciación y los dominios de cada disciplina, Arquitectura y Arquitectura del Paisaje han compartido su atención en el espacio habitado, es decir, en el espacio producido y percibido por las sociedades humanas a lo largo del tiempo y en distintos contextos. Existe por tanto un conocimiento

El parque Micaela Bastidas, obra de la arquitecta paisajista Irene Joselevich y equipo, forma parte de un proceso de recuperación urbana de la zona de Puerto Madero, en Buenos Aires. En torno a este nuevo espacio público se han comenzado a desarrollar múltiples proyectos inmobiliarios residenciales y de servicios.

Ubicado en la comuna de Vitacura y junto al río Mapocho en la zona oriente de Santiago, el parque Bicentenario, obra del arquitecto Teodoro Fernández y equipo, revalorizando antiguos predios baldíos adyacentes al río. Junto al parque, al igual que en Puerto Madero, hoy se observa el rápido crecimiento de edificios habitacionales, comprobando la estrecha relación entre la creación de espacios verdes urbanos y la rentabilidad del mercado del suelo. 
Paseo del embalse Santa Juana, obra de Carlos Martner (fuente: fotografía del autor)

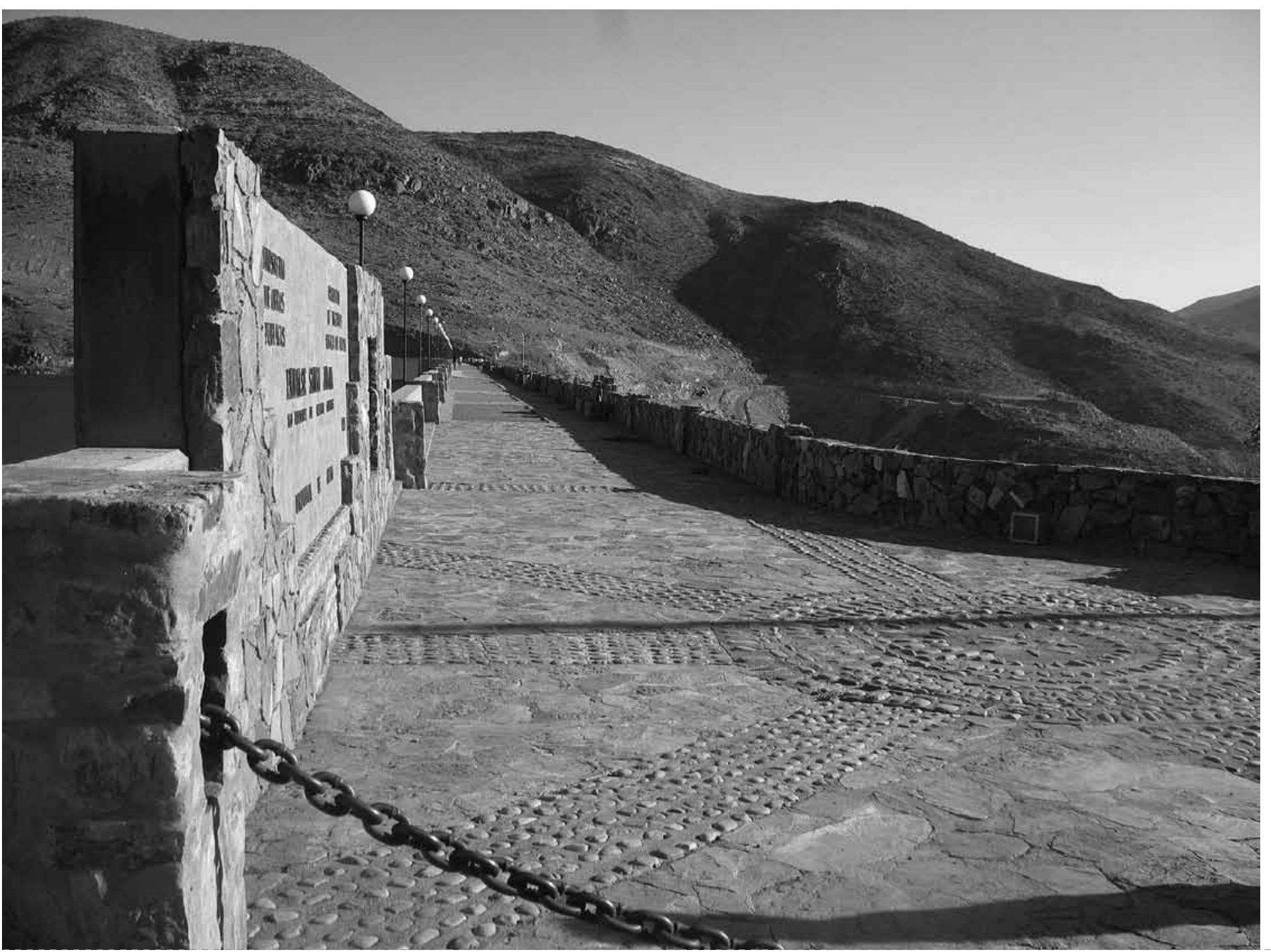

acumulado que necesita ser revisado y actualizado, para obtener de él los medios que permitan la interacción con las variables bióticas, abióticas y antrópicas -materiales y virtuales- que conforman el contexto de actuación tanto para los arquitectos como para los arquitectos del paisaje. Inspiradas en su origen centenario ${ }^{13}$, las Escuelas de Arquitectura del Paisaje deberán tratar de asumir el nuevo rol de la disciplina en la producción del espacio contemporáneo a nivel global, ligado no sólo a parques, jardines o áreas silvestres, sino implicado profundamente en las dinámicas de transformación del territorio: de las infraestructuras, de los recursos ambientales, de los grupos sociales y del patrimonio cultural.

Por otra parte, atendiendo a la lógica relación con la arquitectura y el urbanismo, la abolición de modelos estancos y compartimentados heredados de la modernidad debe ser el inicio del abordaje académico tanto en Arquitectura, como en Arquitectura del Paisaje. Ello requerirá de una articulación epistemológica, metodológica e instrumental entre aquellos temas ligados a la dimensión material de la naturaleza -conformada por seres vivientes, objetos, geomorfologías- y a la dimensión inmaterial de la cultura, sustentada en valores, creencias, costumbres y tradiciones, contextualizadas en un espacio y tiempo determinado.

13 La primera escuela de Arquitectura del Paisaje fue fundada en Harvard el año 1905, por Frederick L. Olmsted hijo. 


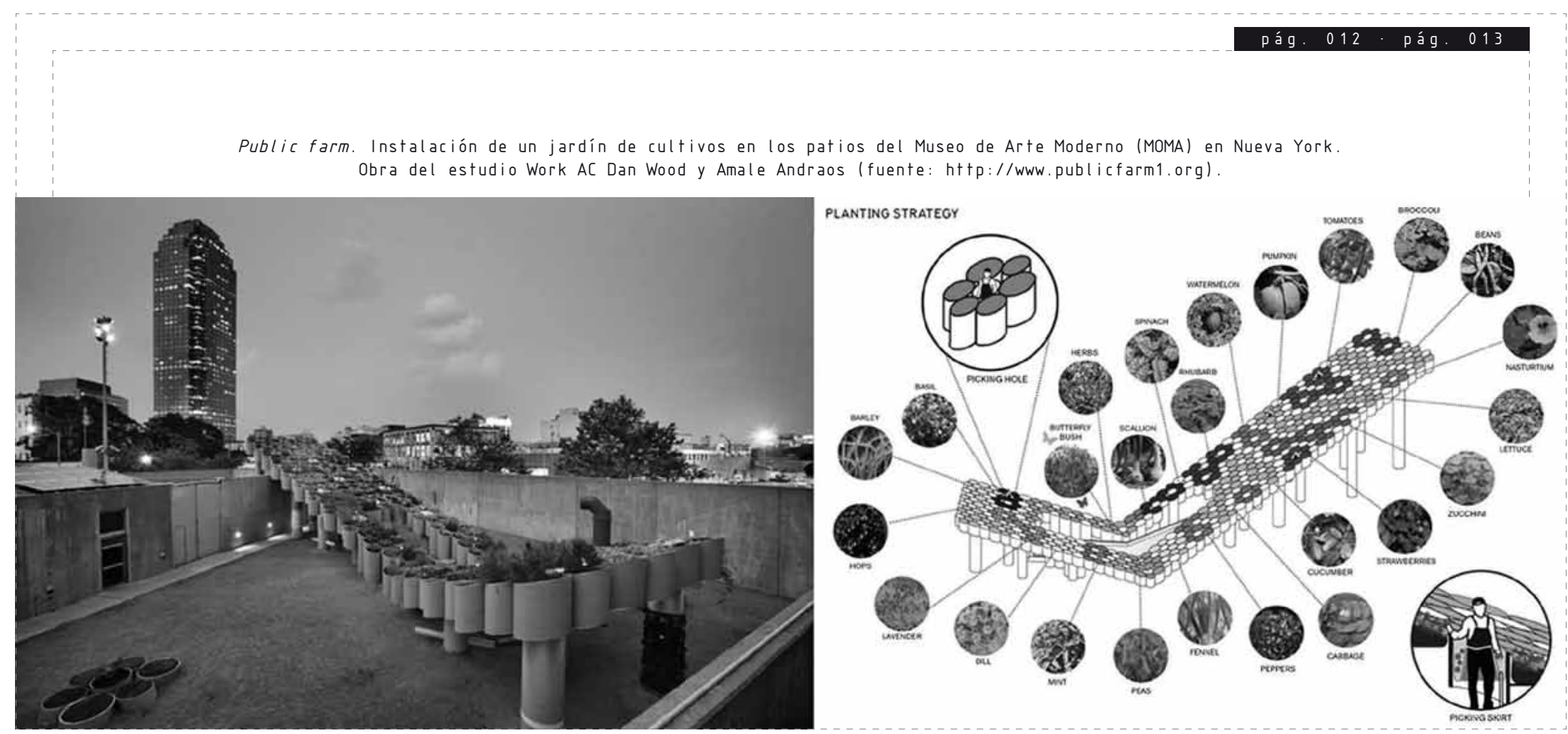

\section{Bibliografía consultada}

- Iñaki Ábalos. Atlas pintoresco. Volumen 1: El observatorio. Barcelona, España: Editorial Gustavo Gili, 2005.

- Iñaki Ábalos. Atlas pintoresco. Volumen 2: Los viajes. Barcelona, España: Editoria Gustavo Gili, 2008.

- Gilles Clemènt. Manifiesto del tercer paisaje. Barcelona, España: Editorial Gustavo Gili, 2007.

- James Corner. «Lifescape - Fresh Kill Parkland». En: Revista Topos: International Review of Landscape Architecture and Urban Design 2005; 51.

- Maria Di Pace et al. Ecología de la ciudad. Buenos Aires, Argentina: Universidad Nacional de General Sarmiento, Libros Prometeo, 2004.
- Pierre Donadieu. La sociedad paisajista. (Edición castellana). La Plata, Argentina: Editorial de la Universidad Nacional de La Plata, 2006.

- Richard Forman. Mosaico territorial para la Región Metropolitana de Barcelona. (Edición castellana). Barcelona, España: Editorial Gustavo Gili, 2004.

- Domingo Gómez Orea. Ordenación del territorio: Una aproximación desde el medio físico. Madrid, España: Instituto Tecnológico Geominero, 1994.

- Robert Holden. Nueva arquitectura del paisaje. Barcelona, España: Editorial Gustavo Gili, 2003.

- Michael Hough. Naturaleza y ciudad. Planificación urbana y procesos ecológicos. (Edición castellana). Barcelona, España: Editorial Gustavo Gili, 1998.
- Ian Mcharg. Proyectar con la naturaleza. (Edición castellana). Barcelona, España: Editorial Gustavo Gili, 2000.

- Osvaldo Moreno. «Paisaje; plataforma de comprensión y gestión de las dinámicas del ambiente y del territorio». En: Hipótesis de paisaje. Córdoba, Argentina: I+P Editorial, 2006.

- Alain Roger. Breve tratado del paisaje España: Editorial Biblioteca Nueva, 2007.

- Milton Santos. La naturaleza del espacio. Técnica y tiempo. Razón y emoción. Barcelona, España: Editorial Ariel SA, 2000

- Graciela Silvestri, Fernando Aliata. El paisaje como cifra de armonía. Buenos Aires, Argentina: Ediciones Nueva Visión, 2001

- Florencio Zoido, De la Vega et al. Diccionario de geografía urbana, urbanismo y ordenación del territorio. Barcelona, España: Editorial Ariel SA, 2000.

\section{Fe de erratas Revista De Arquitectura $\mathbf{N}^{\circ} 18$}

ARTÍCULO "PATRIMONIO ARQUITECTÓNICO INDUSTRIAL: UNA OPORTUNIDAD PARA LA RECONVERSIÓN Y REVITALIZACIÓN EN LA CIUDAD"

Pág. 015 dice: "Ex fábrica Nacional de Vidrios ubicada en avenida Vicuña Mackenna 1348".

Debe decir: "Ex fábrica Nacional de Vidrios ubicada en sector Franklin y San Diego".

Pág. 016 dice: "Ex Central de Leche, ocupaba una manzana completa en torno al antiguo ferrocarril que permitía el mantenimiento de su producción".

Debe decir: "Antigua Fábrica de Sombreros Cintolesi en Quinta Normal, próxima a la estación Yungay". 